\title{
Trauma Mamilar: Cuidados Adotados por Mulheres no Pós-parto
}

\author{
Nipple Trauma: Postpartum Care Adopted by Women
}

Lesiones en el Pezón: Cuidados Adoptados por Mujeres en el Posparto

Maristela Belletti Mutt Urasaki', Camila Inocencio Teixeira ${ }^{1}$, Marina Possato Cervellini²

\begin{abstract}
RESUMO
O trauma mamilar é uma intercorrência frequente no pós-parto e interfere no processo de amamentação por ocasionar desconforto e dor à mulher. O objetivo deste estudo foi conhecer os cuidados adotados por mulheres que apresentaram trauma mamilar no pós-parto. Estudo descritivo, exploratório e de abordagem quantitativa. A amostra foi composta por 112 mulheres com filhos de idade inferior a 2 anos. Os dados foram coletados em parques e praças da zona leste de São Paulo, por meio de formulário composto por questões fechadas e abertas. Todas as participantes amamentaram seus filhos, variando apenas o tempo da amamentação; o trauma mamilar não foi motivo para desmame; $44 \%$ observaram algum tipo de lesão no mamilo, e a maioria em ambas as mamas. Dessas mulheres, 85,4\% recorreram a algum tipo de tratamento, sendo mencionados tratamentos úmidos e secos, isolados ou em associações e correção da pega. Medidas preventivas no pré-natal foram empregadas por $28(30,1 \%)$ gestantes. Conclui-se que é expressivo o número de mulheres com trauma mamilar; algumas possuem informações imprecisas sobre as causas da lesão, como prevenir ou cuidar, constituindo tanto fatores de risco para seu surgimento quanto para seu agravamento.
\end{abstract}

DESCRITORES: Ferimentos e lesões. Mamilos. Aleitamento materno. Estomaterapia.

\begin{abstract}
Nipple trauma is a frequent intercurrence at postpartum and interferes at breastfeeding by causing discomfort and pain to women. The objective of this study was to know the adopted cares by women who had nipple trauma during the postpartum period. This was a descriptive and exploratory study with quantitative approach. The sample included 112 women with children under the age of 2 . The data were collected in parks and squares of the East Zone of São Paulo city, Brazil, by means of a form with closed and open questions. All participants breastfed their children varying only the breastfeeding period; the nipple trauma was no reason for weaning; $44 \%$ noted some type of nipple injury, the majority in both breasts. It was found that $85.4 \%$ had recoursed to some kind of treatment, being mentioned wet or dry treatments, isolated or in associations, and latch correction. Preventive measures in prenatal were employed by 28 (30.1\%) pregnant women. We conclude that the number of women with nipple trauma is expressive; some have inaccurate information about its causes, how to prevent or take care of it, which constitutes risk factors for its onset and worsening.
\end{abstract}

DESCRIPTORS: Wounds and injuries. Nipples. Breast feeding. Stomatherapy.

'Escola de Artes, Ciências e Humanidades da Universidade de São Paulo (USP) - São Paulo (SP), Brasil.

${ }^{2}$ Centro Universitário São Camilo - São Paulo (SP), Brasil.

Endereço para correspondência: Maristela Belletti Mutt Urasaki - Avenida Arlindo Bettio, 1000 - Ermelino Matarazzo - CEP: 03828-000 -

São Paulo (SP), Brasil - E-mail: mari.urasaki@usp.br

Artigo recebido em: 01/03/2016 - Aceito para publicação em: 27/05/2016 


\section{RESUMEN}

El trauma del pezón es intercurrente en el postparto e interfiere en el proceso de amamantamiento por ocasionar incomodad y dolor en las mujeres. El objetivo del estudio fue conocer los cuidados adoptados por las mujeres que tuvieron trauma del pezón durante el postparto. Estudio descriptivo, exploratorio y de abordaje cuantitativo. La muestra fue compuesta por 112 mujeres con hijos menores de 2 años. Los datos fueron recolectados en los parques y las plazas de la Zona Este de São Paulo, Brasil, por medio de formulario compuesto por preguntas cerradas y abiertas. Todas las participantes amamantaron sus hijos, variando solamente el período de amamantamiento; el trauma del pezón no fue razón para el destete; 44\% observaron algún tipo de lesión en el pezón, y la mayoría en ambas mamas. De esas mujeres, 85,4\% recurrieron a algún tipo de tratamiento, siendo mencionados tratamientos húmedos y secos, aislados o en asociaciones, y corrección del agarre. Las medidas de prevención en el prenatal fueron empleadas por 28 (30,1\%) mujeres embarazadas. Se concluye que es significativo el número de mujeres con trauma del pezón; algunas tienen informaciones imprecisas sobre las causas de la lesión, prevención o cuidado, constituyendo tanto factores de riesgo para su surgimiento como su agravamiento.

DESCRIPTORES: Heridas y traumatismos. Pezones. Lactancia materna. Estomaterapia.

\section{INTRODUÇÃO}

A recomendação da Organização Mundial de Saúde (OMS), do Ministério da Saúde (MS) e do Fundo das Nações Unidas para a Infância e Adolescência (UNICEF), é de que a mãe alimente exclusivamente o bebê com leite materno até os seis meses de idade, uma vez que não é necessário nenhum outro alimento nesse período ${ }^{1,2}$.

O leite materno é considerado o alimento mais completo para o recém-nascido; contém todas as proteínas, lipídeos, carboidratos, vitaminas e minerais importantes para o crescimento e desenvolvimento sensorial e cognitivo e é rico em linfócitos e imunoglobulinas que protegem o lactente de infecções. Além disso, o movimento da musculatura realizado pela criança ao sugar a mama auxilia no desenvolvimento da dentição, da fala e na respiração. A amamentação também promove benefícios para a mãe, contribuindo na redução do peso após o parto, no retorno do útero ao seu tamanho normal, minimizando o risco de hemorragia e anemia, e ajudando na redução do risco de diabetes, câncer de mama e de ovário ${ }^{1,3-5}$. Outro importante benefício do aleitamento é o fortalecimento do vínculo afetivo entre mãe e filho. O contato contínuo, quando prazeroso, fortalece os laços afetivos, oportunizando intimidade, sentimentos de segurança e de proteção na criança e de autoconfiança e realização na mulher. É uma forma especial de comunicação entre a mãe e o bebê e uma oportunidade da criança aprender a se comunicar com afeto e confiança ${ }^{1}$.

O processo de amamentação pode sofrer interferência de vários fatores, implicando em prejuízos para a mãe e o bebê, dentre eles destaca-se o trauma mamilar (TM). Essa condição pode ser caracterizada como uma solução de continuidade da pele do mamilo e/ou aréola, lesão visível macroscopicamente, que dificulta o processo de amamentação por ocasionar desconforto e dor à mulher ${ }^{6,7}$.

O TM é uma intercorrência cuja incidência varia de 11 a $96 \%$ durante a primeira semana após o parto. Cerca de 80 a 95\% apresenta algum grau de dor mamilar e 26\% apresentam dor extrema. Como consequência podem ocorrer a interrupção precoce da amamentação e o aumento do uso de mamadeiras e bicos artificiais, favorecendo comorbidades ${ }^{8,9}$. Variáveis obstétricas e neonatais estão associadas ao TM, dentre as obstétricas consideram-se: primiparidade, ausência do companheiro, mamas em condições túrgidas e ingurgitadas, mamilos semiprotusos, malformados e despigmentados, uso impróprio de bombas de extração de leite, uso de cremes e óleos que causam reações alérgicas nos mamilos, uso de protetores de mamilo (intermediários) e exposição prolongada a forros úmidos. Por outro lado, dentre as neonatais estão: prematuridade, presença de freio lingual curto, sucção não nutritiva ou ineficaz, não interrupção da sucção da criança antes de retirá-la do peito, posicionamento incorreto e pega inadequada do recém-nascido durante a amamentação. Os dois últimos são considerados consensualmente como os principais fatores ${ }^{6,7,10,11}$.

Aspectos biomecânicos do aleitamento materno devem ser considerados na lesão mamilar. O mamilo está sob trauma recorrente pela própria sucção do recém-nascido no momento da mamada ${ }^{12}$. Quando ocorre o TM, se não for adequadamente tratado, o acometimento do tecido pode progredir rapidamente e a lesão se tornar grave e extensa. Além disso, 
a solução de continuidade é a porta de entrada para bactérias e fungos que podem causar infecções, como a mastite. A presença de agentes infecciosos pode atrasar o processo de reparação, mesmo quando outros fatores como a pega e o posicionamento do bebê estão $\operatorname{corretos}^{13}$. A presença de dor também pode atrasar o processo de reparação, provavelmente pelo recrutamento de células inflamatórias no leito da lesão ${ }^{14}$. O tempo de cicatrização das lesões é bastante variado, podendo ocorrer por volta de 24 horas ou se prolongar até $28 \mathrm{dias}^{7}$.

No período pós-parto, é comum mulheres adotarem práticas e cuidados populares para a saúde geral ${ }^{15}$; um exemplo é o costume de não comer peixe para não rachar o mamilo. Incluem-se nessas práticas aquelas relacionadas aos cuidados com feridas, principalmente sobre a terapêutica tópica ${ }^{16,17}$. Tais práticas, se inapropriadas, podem comprometer o processo cicatricial de uma lesão mamilar e, consequentemente, dificultar a amamentação e determinar o desmame precoce.

Nesse sentido, considerando os riscos associados ao TM e a importância da amamentação, este estudo teve como objetivo conhecer os cuidados adotados por mulheres que apresentaram TM durante o pós-parto.

Espera-se que os resultados desta pesquisa ofereçam subsídios aos profissionais de saúde para que, em atividades educativas, enfatizem os riscos de cuidados inapropriados à evolução positiva do TM, contribuindo para a melhoria do atendimento à nutriz.

\section{MÉTODO}

Trata-se de um estudo descritivo e exploratório, transversal e de abordagem quantitativa. Na perspectiva das lesões elementares dermatológicas, podem ser consideradas lesões mamilares: o eritema, a equimose, o edema, a vesícula, a erosão, a ulceração, a escoriação e a fissura. Contudo, como não há uma padronização entre os autores para sua definição e classificação, nesta investigação é usado o termo geral trauma ${ }^{7}$.

A população foi composta por 112 mulheres e o critério de inclusão foi ter mais de 18 anos e filhos em idade inferior a 2 anos. A seleção foi realizada por conveniência. Os dados foram coletados em parques e praças da zona leste da cidade de São Paulo. A escolha de uma área pública e não um serviço de saúde foi uma estratégia adotada para que as participantes respondessem aos questionários de forma mais espontânea, sem receio de não corresponderem ao que é preconizado ou informado nos serviços.
Para o levantamento dos dados, foi aplicado um formulário anônimo, construído especificamente para o estudo e composto por questões fechadas e abertas. Partiu-se da seguinte questão: você está amamentando ou amamentou nos últimos 12 meses? Em seguida, o questionário foi dividido em dois blocos. Para aquelas que amamentaram, buscou-se conhecer: incidência do TM, cuidados realizados no pré e pós-parto, fonte do conhecimento e se conheceram outras mulheres que apresentaram o problema e como elas lidaram com o mesmo. No segundo bloco, para aquelas participantes que não amamentaram, investigou-se o motivo e se o TM foi determinante para o desmame. Para respostas afirmativas, foram investigadas as mesmas questões do grupo anterior; já para negativas, se conheceram mulheres que tiveram o problema e como elas cuidaram do quadro. Durante as entrevistas, o termo trauma foi substituído por ferida e rachadura, quando necessário, buscando adaptação ao vocabulário popular referente ao problema estudado.

A análise das informações foi realizada com base na estatística descritiva. Os aspectos éticos elegais envolvendo a pesquisa com seres humanos foram respeitados. A pesquisa foi aprovada pelo Comitê de Ética em Pesquisa da Escola de Artes, Ciências e Humanidades da Universidade de São Paulo, conforme registro na Plataforma Brasil, CAAE 387 54314.7.0000.5390.

\section{RESULTADOS}

Participaram do estudo 112 mulheres com idade mínima de 18 anos e máxima de 42, sendo a média de 26,6 anos. A idade do bebê variou de 1 mês a 2 anos, sendo a média de idade 8,9 meses. Todas as mulheres entrevistadas amamentaram variando apenas o período.

Do total, verificou-se que $77(68,7 \%)$ estavam amamentando no momento da coleta de dados, 16 (14,2\%) não estavam amamentando, mas amamentaram no último ano, e 19 $(16,9 \%)$ não estavam amamentando ou não amamentaram no último ano, mas chegaram a amamentar por curto período.

\section{Dados sobre as mulheres que estavam amamentando e amamentaram nos últimos 12 meses}

Do total de 93 mulheres que estavam amamentando e amamentaram nos últimos 12 meses, 41 (44,1\%) observaram 
algum tipo de trauma no mamilo durante a amamentação, sendo que 37 (90,2\%) observaram lesão em ambas as mamas. Constatou-se que $35(85,4 \%)$ delas recorreram a algum tipo de tratamento. Seis $(14,6 \%)$ aguardaram evolução espontânea e não souberam precisar a qualidade da recuperação. As mulheres citaram tanto cuidados únicos quanto associados, apresentados na Tabela 1.

Das 16 participantes que utilizaram pomadas, tanto associada a outras condutas quanto como tratamento exclusivo, apenas 4 (25\%) souberam indicar o nome do produto ou sua composição. As pomadas mencionadas foram: pomada à base de lanolina (Memê), pomada com lanolina anidra pura (Millar e Lanidrat) e pomada composta por dexpantenol (Bepantol).

Foi solicitado às mulheres que adotaram algum cuidado que avaliassem a conduta empregada. Para a maioria delas, o resultado foi positivo, 33 (94,2\%) afirmaram melhora da condição, 1 (2,8\%) não observou melhora e $1(2,8 \%)$ referiu melhora parcial. A participante que não observou melhora usou pomada amilar e casca de banana, aconselhada por uma amiga; e a que referiu melhora parcial usou pomada, de cor amarela, recomendada pelo hospital. Todas recomendariam a outras mulheres o modo como cuidaram da lesão.

Dentre as 35 mulheres que trataram o TM, 23 (64,8\%) buscaram orientações com profissionais da área da saúde, enquanto 7 (20,0\%) seguiram orientações de familiares e amigos, 2 (5,7\%) buscaram orientações na Internet, 1 (2,8\%) por meio de revistas, 1 (2,8\%) recorreu à farmácia e 1 (2,8\%)

Tabela 1. Cuidados adotados por mulheres que apresentaram trauma mamilar durante a amamentação (n=35). São Paulo, 2015.

\begin{tabular}{|c|c|c|}
\hline Cuidados adotados & $\mathrm{n}$ & $\%$ \\
\hline \multicolumn{3}{|l|}{ Cuidado único } \\
\hline Leite materno & 14 & 40,0 \\
\hline Uso de pomada & 14 & 40,0 \\
\hline Pega correta & 1 & 2,9 \\
\hline \multicolumn{3}{|l|}{ Cuidados associados } \\
\hline Pomada e leite materno & 1 & 2,9 \\
\hline Pomada e casca de banana & 1 & 2,9 \\
\hline Casca de banana e saliva do bebê & 1 & 2,9 \\
\hline $\begin{array}{l}\text { Luz solar, leite materno } \\
\text { e casca de banana }\end{array}$ & 1 & 2,9 \\
\hline Água quente e leite materno & 1 & 2,9 \\
\hline $\begin{array}{l}\text { Água quente, leite materno e } \\
\text { casca de banana }\end{array}$ & 1 & 2,9 \\
\hline Total & 35 & 100 \\
\hline
\end{tabular}

não soube precisar como obteve a informação. As orientações estão descritas na Tabela 2.

O questionamento sobre o conhecimento da causa do TM àquelas mulheres que apresentaram lesão resultou em 11 diferentes razões; as respostas estão relacionadas à própria mama, ao bebê, ao ambiente e ao desconhecimento da mãe em como amamentar, como apresentado na Tabela 3.

Em relação à adoção de medidas durante o pré-natal para prevenir o TM, constatou-se que $28(30,1 \%)$ mulheres realizaram algum tipo de cuidado com as mamas, sendo que

Tabela 2. Orientações dos profissionais de saúde sobre cuidados com o trauma mamilar segundo puérperas ( $n=23)$. São Paulo, 2015.

\begin{tabular}{lcc}
\hline Orientações de profissionais & $\mathbf{n}$ & $\%$ \\
\hline Leite materno & 9 & 39,1 \\
\hline Uso de pomada & 8 & 34,8 \\
\hline Água quente e leite & 1 & 4,3 \\
\hline Água quente, leite & 1 & 4,3 \\
e casca de banana & 1 & 4,3 \\
\hline Anti-inflamatório tópico & 1 & 4,3 \\
Luz solar, leite materno & 1 & 4,3 \\
e casca de banana & 1 & 4,3 \\
Correção da pega & 23 & 100,0 \\
\hline Uso de pomadas e leite materno & & \\
Total &
\end{tabular}

Tabela 3. Causas do trauma mamilar durante a amamentação, segundo mulheres que apresentaram lesão (n=46). São Paulo, 2015.

\begin{tabular}{lcc}
\hline Causas do trauma mamilar & $\mathbf{n}$ & $\mathbf{\%}$ \\
\hline Pega incorreta & 13 & 28,3 \\
\hline Forte sucção do bebê no mamilo & 6 & 13,0 \\
\hline Ressecamento do mamilo & 4 & 8,7 \\
\hline Ausência do mamilo & 3 & 6,5 \\
\hline Excesso de mamadas & 2 & 4,3 \\
\hline Falta de orientação & 2 & 4,3 \\
\hline Saliva do bebê & 2 & 4,3 \\
\hline Ingurgitamento mamário & 2 & 4,3 \\
\hline Falta de experiência & 2 & 4,3 \\
\hline Temperatura ambiente fria & 1 & 2,2 \\
\hline Bebê afoito & 1 & 2,2 \\
Não souberam informar & 8 & 17,4 \\
\hline Total & 46 & 100,0 \\
\hline
\end{tabular}


$10(35,7 \%)$ observaram o trauma posteriormente durante a amamentação (Tabela 4). As respostas variaram entre cuidados secos, úmidos, aplicação de atrito, evitar produtos e proteção.

O conhecimento para realização dos cuidados durante o pré-natal foi adquirido com: 12 (42,8\%) profissionais da saúde, 7 (25\%) familiares e amigos, $2(7,1 \%)$ pesquisas na Internet, 2 (7,1\%) com farmacêuticos, 1 (3,5\%) em curso, $1(3,5 \%)$ sozinha e $3(10,7 \%)$ não souberam informar a fonte.

\section{Dados sobre as mulheres que amamentaram por curto período}

As $19(16,9 \%)$ mulheres que não estavam amamentando na data da entrevista, mas que amamentaram entre os 24 e 13 meses anteriores, afirmaram não ter apresentado TM, portanto, não foi a causa do desmame. Os motivos para a interrupção da amamentação foram relacionados à mãe (uso de medicação), ao bebê (não aceitação, deixou de mamar espontaneamente, uso de complemento por baixo peso e internação) e à mama (sem leite e ausência de mamilo).

Todas as 112 participantes foram questionadas se conheciam outras mulheres que apresentaram TM durante a amamentação. Do total, 74 (66,1\%) afirmaram ter conhecimento de mulheres que apresentaram o problema, 57 $(77,0 \%)$ souberam informar o cuidado prestado por essa outra pessoa, e 1 afirmou que sua conhecida não tomou nenhuma medida. Foram mencionados diversos cuidados, apresentados na Tabela 5.
Dentre as 112 participantes, $9(8,0 \%)$ nunca haviam ouvido falar sobre o trauma, 27 (24,1\%), além de não terem identificado TM em seus mamilos/aréolas, também desconheciam mulheres que apresentaram o problema.

Tabela 5. Cuidados adotados com o trauma mamilar por mulheres conhecidas das entrevistadas ( $n=56)$. São Paulo, 2015.

\begin{tabular}{lcc}
\hline Cuidados adotados & $\mathbf{n}$ & $\%$ \\
\hline Cuidado único & & \\
\hline Pomada & 13 & 33,9 \\
\hline Leite materno & 23,2 \\
\hline Casca de banana & 10,7 \\
\hline Água quente & 2 & 3,6 \\
Batata & 1 & 1,8 \\
Hidratante & 1 & 1,8 \\
Bico de silicone & 1 & 1,8 \\
Cuidados associados & & \\
Casca de banana e pomada & 5 & 8,9 \\
Pomada e bico de silicone & 2 & 3,6 \\
Casca de banana e & 2 & 3,6 \\
polpa de mamão & 1 & 1,8 \\
\hline Leite materno e pomada & 1 & 1,8 \\
Leite materno e correção da pega & 1 \\
\hline Leite materno e sol nas mamas & 1 & 1,8 \\
Casca de banana & 1 & 1,8 \\
e casca de melão & 56 & 100 \\
\hline Total &
\end{tabular}

Tabela 4. Cuidados para prevenção do trauma mamilar durante o pré-natal e lesão pós-parto ( $n=32)$. São Paulo, 2015.

\begin{tabular}{|c|c|c|c|c|}
\hline \multirow[t]{2}{*}{ Cuidados adotados no pré-natal } & \multicolumn{2}{|c|}{ Pré-natal } & \multicolumn{2}{|c|}{$\begin{array}{c}\text { Trauma mamilar } \\
\text { no pós-parto }\end{array}$} \\
\hline & $\mathrm{n}$ & $\%$ & $\mathrm{n}$ & $\%$ \\
\hline Esfregar buchas, esponjas ou toalhas nos mamilos & 9 & 28,1 & 3 & 9,4 \\
\hline Aplicar pomada nos mamilos & 7 & 21,9 & 1 & 3,1 \\
\hline Massagear os mamilos & 5 & 15,6 & 2 & 6,3 \\
\hline Tomar sol nas mamas (antes das 10 e depois das 16 horas) & 3 & 9,4 & 2 & 6,3 \\
\hline Aplicar óleo corporal nas mamas & 3 & 9,4 & 1 & 3,1 \\
\hline Aprender a técnica correta para a pega & 1 & 3,1 & - & - \\
\hline Evitar sabão nos mamilos & 1 & 3,1 & - & - \\
\hline Evitar hidratante nos mamilos & 1 & 3,1 & 1 & 3,1 \\
\hline Aplicar o próprio leite nos mamilos & 1 & 3,1 & - & - \\
\hline Utilizar conchas de proteção nos mamilos & 1 & 3,1 & - & - \\
\hline Total & 32 & 100 & 10 & 31,3 \\
\hline
\end{tabular}




\section{DISCUSSÃO}

A amamentação ocorreu para todas as mulheres, ainda que o período tenha variado entre as participantes. O TM não foi motivo de desmame ou interrupção temporária para nenhuma delas.

A maioria das mulheres que apresentaram TM optou por tratar. Quase todas mencionaram tratamentos tópicos, apenas uma afirmou ter realizado a correção da pega, embora 20 tenham citado a pega e fatores relacionados (bebê afoito e sucção forte) como causas do TM. Nenhuma falou sobre o posicionamento correto do bebê. É possível que elas não tenham associado essas condutas como parte do tratamento, limitando-se a abordar o uso de produtos locais.

A literatura mostra que a pega correta é uma medida fundamental a ser adotada na prevenção e no tratamento das lesões mamilares, já que é reconhecida como a causa maior para a ocorrência dos traumas mamilares ${ }^{1,7,10,11,18-21}$. A sucção do bebê e os movimentos de mandíbula, língua e lábios realizados ao longo das frequentes mamadas promovem movimento, compressão e extensão mamilar ${ }^{12}$. Esse processo pode ocasionar dor e dano ao tecido e, quando a pega está incorreta, há maior força de pressão intraoral do bebê, ocasionando numa maior extensão do tecido mamilar ${ }^{22}$.

A pega correta do bebê é considerada aquela que atende ao menos quatro dos cinco comportamentos: boca bem aberta, abocanhamento de todo mamilo e boa parte da aréola; língua do lactente no assoalho da boca; lábio inferior com projeção para fora; queixo do lactente tocando a mama e lactente mantendo a pega da aréola ${ }^{23}$.

O posicionamento incorreto do bebê e da mãe durante a amamentação pode ser fator de risco ao $\mathrm{TM}^{6,20,21}$. O posicionamento apropriado envolve: puérpera relaxada e lactente confortável, cabeça e corpo do lactente alinhados, corpo do lactente voltado lateralmente e próximo ao da puérpera e quadril do lactente apoiado. Já o desfavorável envolve: puérpera com ombros tensos e inclinada sobre o lactente, lactente com o pescoço e cabeça virados para a mama, corpo do lactente distante da puérpera e apenas ombros ou cabeça apoiados ${ }^{23}$.

Tanto a pega quanto o posicionamento adequados são considerados medidas de proteção ${ }^{19}$, devem ser mantidos durante todo o processo de amamentação e todas as mães deveriam ser enfaticamente orientadas a esse respeito, uma vez que uma única intervenção sobre pega e posicionamento corretos na amamentação não é suficiente para melhorá-los ou reduzir os TM ${ }^{24}$.
As duas medidas para tratamento do TM mais citadas pelas participantes, leite materno e uso de pomadas, estão amparadas nos conceitos de tratamento de feridas por meio de ambiente úmido. As evidências apontam vantagens na recuperação tecidual quando a lesão está sob hidratação controlada, tais quais: facilita o processo de cicatrização da ferida, impede a desidratação, melhora a angiogênese e a síntese de colágeno e aumenta a degradação do tecido morto e fibrina. Esses benefícios contribuem para a melhora estética da ferida e diminuição da dor. Além disso, o ambiente úmido não aumenta o risco de infecção em comparação com a terapia sob ambiente seco ${ }^{25}$. Embora esse conhecimento esteja bem sedimentado, existem lacunas relacionadas ao tratamento e aos cuidados efetivos com TM.

$\mathrm{O}$ leite materno tem sido recomendado pelo MS e pela UNICEF para tratar o $\mathrm{TM}^{1,2}$. Suas propriedades protetoras gerais são inquestionáveis, uma vez que participa da função imunitária, anti-inflamatória e do crescimento e desenvolvimento tecidual do bebê. Entretanto, os resultados de pesquisas sobre sua ação local não são conclusivos, principalmente no que diz respeito a sua superioridade comparada ao uso da lanolina. Vieira et al. ${ }^{26}$ realizaram uma revisão sistemática sobre intervenções para o TM, analisando os seguintes tratamentos: lanolina, lanolina em associação com conchas de proteção,leite materno, hidrogel, revestimentos de película adesiva de polietileno, spray contendo clorexidina alcoólica e água destilada. A análise dos autores apontou evidências favoráveis tanto para o uso do leite materno após cada mamada quanto para o uso de lanolina isolada ou combinada à concha. Outro estudo recente, não contemplado na revisão mencionada, encontrou resultados mais favoráveis ao uso de leite materno comparado ao da lanolina anidra. Porém, a aplicação do leite foi combinada ao uso da concha de proteção dos mamilos, o que possivelmente justificaria o resultado de processo cicatricial mais rápido e melhor alívio da dor na região areolomamilar ${ }^{23}$.

A forma de usar o leite materno é simples: recomenda-se que as mulheres espalhem o próprio leite pela região mamilar após cada mamada, sem a necessidade de qualquer limpeza do mamilo na mamada seguinte ${ }^{18}$.

Sobre o uso de pomadas, a maioria das mulheres deste estudo não soube indicar o nome do produto nem o seu componente, dificultando a análise desse dado. Importa observar que a literatura não é convergente nesse aspecto. A alegação para contraindicar produtos tópicos está baseada principalmente na possibilidade de interferirem nas propriedades 
bacteriostáticas e de lubrificação fisiológicas da área do mamilo e aréola, predispondo ao surgimento do trauma. Por outro lado, a defesa, especificamente da indicação da pomada à base de lanolina, baseia-se em seus efeitos positivos no processo de cicatrização. $O$ produto forma uma barreira que impede a perda da umidade natural das camadas mais profundas da pele e aumenta a velocidade de proliferação das células epiteliais, diminui a formação de tecido desvitalizado e crostas e, desse modo, reduz o tempo de cicatrização ${ }^{13,19}$. Outra vantagem é o fato de dispensar a limpeza do mamilo antes da próxima mamada ${ }^{23}$.

É necessário considerar que as pesquisas sobre o uso da lanolina precisam avançar, pois os resultados existentes se apoiam em procedimentos metodológicos diversos, tais como o período de acompanhamento das lesões, a formulação da lanolina (purificada ou não), a origem do produto (manipulação, laboratórios comerciais, farmácias de universidades $)^{27}$ e a associação ou não com outros cuidados.

Vale advertir que pomadas que necessitam de remoção deveriam ser contraindicadas durante a amamentação. Uma vez que a pele da região areolomamilar sofre frequentes fricções pela suç̧ão do bebê nas mamadas, a necessidade de remoção de pomadas antes das mamadas gera outra fricção, o que pode facilitar o aparecimento do $\mathrm{TM}^{24}$.

A despeito de estudos controversos, não há evidências sobre qualquer contraindicação para o uso do leite materno, além disso, o custo é zero e é de fácil aplicação, o que o torna bastante apropriado ${ }^{26}$. Soma-se às suas vantagens as propriedades anti-infecciosas, o que, pelo menos em teoria, ajudariam também a prevenir uma importante complicação das lesões que é a mastite ${ }^{28}$.

O uso da casca de banana e de melão, polpa de mamão e batata, práticas citadas pelas participantes tanto para prevenção quanto para o tratamento do TM, não encontra respaldo na literatura. No passado, acreditava-se que a utilização de produtos naturais como esses não trazia danos à saúde. Pesquisas recentes esclarecem que essas substâncias podem trazer prejuízos à saúde da mãe e do bebê. As cascas de banana e de mamão têm toxinas próprias da fruta, que em bebês menos resistentes podem causar infecções intestinais e reações alérgicas ${ }^{29}$. No caso específico do mamão, um problema enfrentado com o uso da polpa da fruta é a impossibilidade de saber a concentração exata da papaína que está sendo aplicada. As nutrizes apreciam o uso da casca de melão, banana e mamão alegando que deixam a mama fresca e aliviam a dor das fissuras mamárias ${ }^{30}$.
É importante ressaltar que algumas práticas de cuidados são transmitidas de geração em geração, tendo origem nos sucessos e insucessos ocorridos. O meio familiar é um importante recurso que as mulheres buscam para garantir saúde e bem-estar, porém às vezes os ensinamentos se contrapõem aos propostos pelos profissionais de saúde, sendo fundamental que as condutas prejudiciais ao bem-estar do binômio mãe e bebê sejam problematizadas junto às mulheres ${ }^{15,30}$.

Foi mencionado o tratamento seco por meio de banho de luz solar. Essa prática, também encontrada em outro estudo $^{18}$, pode ser mais prejudicial do que benéfica, pois, como citado anteriormente, a cicatrização de feridas é mais eficiente se as camadas internas da epiderme se mantiverem úmidas ${ }^{25,28}$. A exposição ao sol ainda tem sido recomendada como medida preventiva ${ }^{18}$.

Não foram encontrados estudos sobre o uso de água quente para tratar a lesão; os benefícios advindos da vasodilatação resultante podem trazer algum conforto para a mãe com dor nos mamilos ${ }^{31}$.

Quanto ao uso da saliva do bebê como forma de tratamento do TM, os estudos analisados não mencionam esse aspecto. Talvez popularmente se estabeleça alguma associação com a maneira como os animais domésticos instintivamente tratam suas próprias feridas ao se lamberem.

Conchas de proteção de mamilos não foram citadas para tratamento, foi mencionada por uma das entrevistadas como medida usada no pré-natal. Esses dispositivos são indicados por profissionais da área. O mercado nacional e internacional possui diversas marcas e opções de modelos de conchas, em vários tipos de materiais, sendo que cada um tem recomendações específicas de uso segundo seus fabricantes ${ }^{23}$. Esses materiais devem possuir orifícios de ventilação, pois a inadequada circulação de ar no mamilo e na aréola pode reter umidade e calor, tornando o tecido mais vulnerável a macerações e infecções ${ }^{1}$. O uso de conchas tem sido indicado no período gestacional para auxiliar na preparação e formação dos mamilos e no pós-parto para o tratamento do TM. Entretanto, o uso de conchas protetoras entre as mamadas para evitar o atrito da área lesada com a roupa é uma recomendação que necessita de avaliação de riscos e benefícios. A sua eficácia isolada não foi avaliada em estudos $\operatorname{clínicos}^{23}$.

Intervenções que têm recomendação forte de contraindicação para TM são: limpeza especial dos mamilos com água estéril antes e após as mamadas; aplicação de pomada após cada mamada e sua remoção antes da próxima mamada e o uso do spray comercial cicatrizante à base de esteroide e antibiótico ${ }^{24}$. 
Identificou-se neste estudo que os cuidados adotados pelas conhecidas das participantes foram semelhantes aos delas próprias.

A maioria das mulheres tinha conhecimento sobre as causas do TM. Além de pega incorreta, bebê afoito e forte sucção, dois importantes fatores foram mencionados: ausência de mamilo e ingurgitamento mamário. Os bebês de mulheres com mamilos anômalos (planos, umbilicados e semiumbilicados) muitas vezes apresentam dificuldade em apreender a região do mamilo areolar adequadamente e, havendo uma insistência na tentativa de apreensão, pode ocorrer lesão. $\mathrm{O}$ ingurgitamento mamário também pode ser considerado causador do TM, já que provoca uma alteração no padrão de sucção do recém-nascido ${ }^{11,31}$. Quanto à forte sucção do bebê no mamilo, há controvérsias, sugerindo que a própria sucção do lactente poderia ocasionar o $\mathrm{TM}^{23}$.

As mulheres, de forma assertiva, apontaram a falta de experiência e orientação como causas do TM.Dentre as respostas incorretas (ressecamento do mamilo, saliva do bebê e temperatura ambiente) chama atenção a citação sobre o excesso de mamadas. Esse conhecimento pode interferir na prática da amamentação, levando a mulher à interrupção temporária da mamada e aumentando o risco do ingurgitamento mamário. Ressalta-se também o fato de 19,5\% das mulheres que apresentaram o TM desconhecerem sua causa.

Quanto ao preparo dos mamilos durante a gestação, estudos contraindicam o uso de cremes, óleos, pomadas, buchas e toalhas, pois promovem descamação da pele na região mamilo-areolar, deixando-a mais sensível e predispondo ao aparecimento de TM ${ }^{11}$. Por outro lado, são positivas práticas como: aprender a técnica correta para a amamentação; banhos de sol e secagem dos mamilos íntegros ao ar livre, uma vez que o sol ajuda a camada externa da pele íntegra a se manter seca e saudável; e aleitamento materno sob livre demanda, pois evita o ingurgitamento mamário ${ }^{19}$.

Neste estudo, identificou-se que a maioria das mulheres com TM buscou orientação da equipe de saúde. Embora medidas recomendáveis tenham sido orientadas por profissionais, medidas não recomendadas também foram indicadas, evidenciando a necessidade de atualização das equipes de saúde para o manejo do TM, fato também constatado por Montrone et al. ${ }^{18}$.

Para que o aleitamento materno tenha êxito, as mulheres necessitam do apoio de todo o sistema de saúde durante a gravidez e pós-parto. Idealmente, todos os profissionais de saúde com quem as gestantes e puérperas tenham contato devem estar comprometidos com a promoção do aleitamento materno e ser capazes de fornecer informações apropriadas ${ }^{32}$.

\section{CONCLUSÃO}

Os resultados desta pesquisa mostram expressividade no número de nutrizes que afirmaram ter apresentado TM. Algumas possuem informações imprecisas sobre as causas da lesão, como prevenir e cuidar, constituindo-se tanto fator de risco para o surgimento do problema quanto para seu agravamento. Além disso, as mulheres revelaram que poderiam ser multiplicadoras de informação.

Verificou-se ainda que algumas informações incorretas procederam de profissionais de saúde. Dessa forma, é fundamental investir nos processos educativos das equipes de saúde para que o manejo adequado da prevenção e do tratamento do TM alcance o maior número de mulheres, contribuindo, dessa forma, para que práticas não recomendadas deixem de ser utilizadas.

\section{REFERÊNCIAS}

1. Brasil. Ministério da Saúde. Secretaria de Atenção à Saúde. Departamento de Atenção Básica. Saúde da criança: aleitamento materno e alimentação complementar. Cadernos de Atenção Básica n 23. 2. ed. Brasília: Ministério da Saúde; 2015. 184p.

2. Fundo das Nações Unidas para a Infância (UNICEF). Iniciativa Hospital Amigo da Criança. Módulo 3: promovendo e incentivando a amamentação em um Hospital Amigo da Criança: curso de 20 horas para equipes de maternidade. Brasília: Ministério da Saúde; 2009. 276p.
3. Silva EF, Muniz F, Cecchetto FH. Aleitamento materno na prematuridade: uma revisão integrativa. Rev Enferm UFSM. 2012;2(2):434-41.

4. Fonseca AL, Albernaz EP, Kaufmann CC, Neves IH, Figueiredo VL. Impacto do aleitamento materno no coeficiente de inteligência de crianças de oito anos de idade. J Pediatr (Rio J). 2013;89(4):346-53.

5. Oddy WH. Breastfeeding in the first hour of life protects against neonatal mortality. J Pediatr (Rio J). 2013;89(2):109-11. 
6. Coca KP, Gamba MA, Silva RS, Abrão AC. Does breastfeeding position influence the onset of nipple trauma? Rev Esc Enferm USP. 2009;43(2):446-52.

7. Cervellini MP, Gamba MA, Coca KP, Abrão AC. Lesões mamilares decorrentes da amamentação: um novo olhar novo para um problema conhecido. Rev Esc Enferm USP. 2014;48(2):346-56.

8. Barbosa MB, Palma D, Domene SM, Taddei JA, Lopez FA. Fatores de risco associados ao desmame precoce e ao período de desmame em lactentes matriculados em creches. Rev Paul Pediatr. 2009;27(3):272-81.

9. Parizotto J, Zorzi NT. Aleitamento materno: fatores que levam ao desmame precoce no município de Passo Fundo, RS. Mundo Saúde. 2008;32(4):466-74.

10. Weigert EM, Giugliani ER, França MC, Oliveira LD, Bonilha A, Espírito Santo LC, et al. Influência da técnica de amamentação nas frequências de aleitamento materno exclusivo e lesões mamilares no primeiro mês de lactação. J Pediatr (Rio J). 2005;81(4):310-6.

11. Coca KP, Gamba MA, Silva RS, Abrão AC. Factors associated with nipple trauma in the maternity unit. J Pediatr (Rio J). 2009;85(4):341-5.

12. Elad D, Kozlowskky P, Blum O, Laine AF, Po MJ, Botzer E, et al. Biomechanics of milk extraction during breast-feeding. Proc Natl Acad Sci USA. 2014;111(14):5230-5.

13. Abou-Dakn M, Fluhr JW, Gensch M, Wöckel A. Positive effect of HPA lanolin versus expressed breastmilk on painful and damaged nipples during lactation. Skin Pharmacol Physiol. 2011;24(1):27-35.

14. Chaves ME, Araújo AR, Santos SF, Pinotti M, Oliveira LS. LED phototherapy improves healing of nipple trauma: a pilot study. Photomed Laser Surg. 2012;30(3):172-8.

15. Stefanello J, Nakano AM, Gomes FA. Beliefs and taboos related to the care after delivery: their meaning for a women group. Acta Paul Enferm. 2008;21(2):275-81.

16. Alcoforado $\mathrm{CL}$, Santo $\mathrm{FH}$. Saberes e práticas dos clientes com feridas: um estudo de caso no município de Cruzeiro do Sul, Acre. Rev Min Enferm. 2012;16(1):11-7.

17. Silva RS, Matos LS, Araújo EC, Paixão GP, Costa LE, Pereira A. Popular practices in health: self-care to wounds of users of medicinal plants. Rev Enferm UERJ. 2014;22(3):389-95.

18. Montrone AV, Arantes Cl, Nassar AC, Zanon T. Trauma mamilar e a prática de amamentar: estudo com mulheres no início da lactação. Rev APS. 2006;9(2):168-74.
19. Coca KP, Abrão AC. An evaluation of the effect of lanolina in healing nipple injuries. Acta Paul Enferm. 2008;21(1):11-6.

20. Moraes M, Silva L, Faliú B, Sosa C. Técnica de alimentación a pecho y aparición de trauma del pezón previo al alta hospitalaria. Arch Pediatr Urug. 2011;82(1):10-7.

21. Abd-Elsalam S, Hamido S, Howyida SA. Effect of using pharmacological versus alternative therapy on traumatic nipples for lactating mothers. J Am Sci. 2011;7(11):485-96.

22. McClellan HL, Kent JC, Hepworth AR, Hartmann PE, Geddes DT. Persistent nipple pain in breastfeeding mothers associated with abnormal infant tongue movement. Int J Environ Res Public Health. 2015;12(9):10833-45.

23. Vieira F. Efeito da lanolina anidra comparado ao leite materno combinado à concha de proteção para tratamento da dor e do trauma mamilar em lactantes: ensaio clínico randomizado [Tese de doutorado]. Goiânia: Universidade Federal de Goiás; 2013.

24. Costa AA, Souza EB, Guimarães JV, Vieira F. Evidências das intervençõesna prevenção do trauma mamilar naamamentação: revisão integrativa. Rev Eletr Enferm. 2013;15(3):790-801.

25. Junker JP, Kamel RA, Caterson EJ, Eriksson E. Clinical impact upon wound healing and inflammation in moist, wet, and dry environments. Adv Wound Care. 2013;2(7):348-56.

26. Vieira F, Bachion MM, Mota DD, Munari DB. A systematic review of the interventions for nipple trauma in breastfeeding mothers. J Nurs Scholarsh. 2013;45(2):116-25.

27. Joanna Briggs Institute (JBI). The management of nipple pain and/or trauma associated with breastfeeding. Aust Nurs J. 2009;17(2):32-5.

28. Giugliani ER. Problemas comuns na lactação e seu manejo. 」 Pediatr. 2004;80(5 Supl):S147-4.

29. Vaucher AL, Durman S. Amamentação: crenças e mitos. Rev Eletr Enferm. 2005;7(2):207-14.

30. Acosta DF, Gomes VL, Kerber NP, Costa CF. Influências, crenças e práticas no autocuidado das puérperas. Rev Esc Enferm USP. 2012;46(6):1327-33.

31. Shimoda GT, Silva IA, Santos JL. Características, frequência e fatores presentes na ocorrência de lesão de mamilos em nutrizes. Rev Bras Enferm. 2005;58(5):529-34.

32. Cruz SH, Germano JA, Tomasi E, Facchini LA, Piccini RX, Thumé E. Orientações sobre amamentação: a vantagem do Programa de Saúde da Família em municípios gaúchos com mais de 100.000 habitantes no âmbito do PROESF. Rev Bras Epidemiol. 2010;13(2):259-67. 